\title{
Correlation of serum IgE levels and clinical manifestations in patients with actinic prurigo*
}

\author{
Juan Carlos Cuevas-Gonzalez ${ }^{1}$ \\ Maria Elisa Vega-Memije ${ }^{2}$ \\ Luciano Dominguez-Soto ${ }^{2}$
}

\author{
Zahide Lievanos-Estrada ${ }^{2}$ \\ Maria Teresa Hojyo-Tomoka
}

DOI: http:/ /dx.doi.org/10.1590/abd1806-4841.20163941

\begin{abstract}
BACKGROUND: Actinic prurigo is an idiopathic photodermatosis, the pathophysiology of which has been hypothesized to involve subtype IV type $b$ (Th2) hypersensitive response, whereby IL4, IL5, and IL13 are secreted and mediate the production of B cells, IgE, and IgG4.

OвJестіves: To examine the association of serum IgE levels and the clinical severity of injuries.

Methods: This case-control study comprised patients with a clinical and histopathological diagnosis of actinic prurigo, as well as clinically healthy subjects, from whom 3cc of peripheral blood was taken for immunoassay. Cases were classified by lesion severity as mild, moderate, and severe. Descriptive statistics were analyzed, and chi-square test was performed.

RESULTS: We included 21 actinic prurigo patients and 21 subjects without disease; 11 patients with actinic prurigo had elevated serum IgE levels, and 10 had low serum levels. Six actinic prurigo (AP) patients with elevated serum levels of IgE had moderate injuries, 4 had severe injuries, and 1 had minor injuries. Eight out of 10 patients with normal IgE levels presented with minor injuries in the clinical evaluation. The 21 controls did not have increased serum IgE levels.

CONCLUSIONS: Elevated IgE levels are associated with moderate to severe clinical lesions, suggesting that actinic prurigo entails a type IV subtype b hypersensitivity response in which Th2 cells predominate.
\end{abstract}

Keywords: Immunoglobulin E; Photosensitivity disorders; Skin manifestations

\section{INTRODUCTION}

Actinic prurigo (AP) is an idiopathic photodermatosis, that develop bilaterally and symmetrically, affecting predominantly areas of the face, neck, trunk, and extremities, particularly on the nasal dorsum, zygomatic arches, lower lip, and conjunctiva. ${ }^{1,2}$ Since it is extremely pruritic, excoriations, serohematic crusts, areas of lichenification, scars, and residual hypo- or hyperpigmentation appear. ${ }^{1-5}$
IgE was first discovered in 1966 and later implicated as the mediator of type I hypersensitivity reactions. Quantification of IgE is part of the comprehensive assessment of patients with allergic conditions. ${ }^{6}$ However, IgE, produced by B cells, is also involved in other subtypes of hypersensitivity reactions (IV b). ${ }^{7}$

To understand the pathophysiology of AP, we performed this study to examine serum IgE levels in $\mathrm{AP}$ and associate them with the clinical manifestation of this disease.

Received on 14.08.2014

Approved by the Advisory Board and accepted for publication on 09.03.2015

Work performed at the Department of Dermatology, Dr. Manuel Gea González General Hospital

Financial Support: None.

Financial support: Department of Dermatology.

Conflict of interest: None

Juarez University of the State of Durango - Durango, Mexico.

Dr. Manuel Gea González General Hospital - Mexico City, Mexico.

(C)2016 by Anais Brasileiros de Dermatologia 


\section{METHODS}

This case-control study was conducted in the Department of Dermatology, at the Dr. Manuel Gea Gonzalez General Hospital, in Mexico City.

We included 21 patients with a clinical diagnosis of AP confirmed by histopathology, as well as 21 clinically healthy subjects who visited the hospital for other reasons-mainly cosmetic-excluding those with other allergic diseases.

Both groups were asked to sign consent forms. Detailed histories were taken, and in the physical examination, 3cc of peripheral blood was drawn for the immunoassay.

Cases were grouped by lesion severity: into mild, moderate, and severe:

- Mild: few papular lesions or excoriations on photo-exposed sites.

- Moderate: papular lesions, excoriations, and moderate pruritus.

- Severe: papules, excoriations, cheilitis, conjunctival disease, and severe pruritus.

The experimental procedures began on completion of the clinical elements of the project.

The 2-step Access Total IgE sandwich assay was performed, in which the sample was added to a reaction vessel with paramagnetic particles that were coated by goat-anti-mouse:anti-mouse IgG complexes.

The reaction vessel was separated by a magnetic field and washed, removing material that was not bound to the solid phase. Alkaline phosphatase-conjugated anti-IgE equine was added and the reaction was separated and washed to remove unbound conjugate.

Lumi-phos* 530 chemiluminescent substrate was added to the reaction, and the light generated was measured on a luminometer (light production was directly proportional to the concentration of $\operatorname{IgE}$ in the sample) using the DXi 800 Access System and Total IgE reagent. The reference range was 1.31-165.3 $\mathrm{UI} / \mathrm{mL}$. The variable was dichotomized (normal and elevated levels of IgE) between cases and healthy subjects, and the groups were homogeneous by $\mathrm{X}^{2}$ test.

The database and statistical analysis was performed using SPSS, version 20 (Chicago, IL, USA).

\section{RESULTS}

Of the 21 patients with a confirmed diagnosis of $\mathrm{AP}, 13(62 \%)$ were female and $8(38 \%)$ were male. The mean age was 26.86 years (range $7-47)$. Sixteen of the 21 controls $(76 \%)$ were women.

Eleven (52.3\%) AP patients had elevated serum levels of IgE, of whom $9(82 \%)$ were women. Ten of the patients with high serum levels $(91 \%)$ were being treated with thalidomide, and $1(9 \%)$ was on topical steroids. Table 1 shows the IgE levels of cases and con-
TABLE 1: Controls show stable levels of IgE versus patients with actinic prurigo

\begin{tabular}{llll}
\hline & \multicolumn{2}{l}{ IgE levels } & \multirow{2}{*}{ Total } \\
\cline { 2 - 3 } & Normal & High & \\
\hline Healthy subjects & 21 & 0 & 21 \\
Patients with AP & 10 & 11 & 21 \\
\hline$X^{2}=14.90, p=.001$ & & &
\end{tabular}

trols, while tables 2 and 3 list their clinical profiles and relationship with IgE levels.

Twenty-one controls (100\%) and 10 AP patients (47.7\%) had low serum IgE levels (maximum $80 \mathrm{U} / \mathrm{ml}$ ). Six (54.5\%) AP patients with elevated serum IgE levels had moderate injuries, $4(36.4 \%)$ had severe injuries, and $1(9.1 \%)$ had minor injuries.

At the time of the clinical evaluation, 8 (80\%) patients with normal levels of IgE had minor injury, 1 $(10 \%)$ had moderate injury, and the remainder $(10 \%)$ had no lesions.

\section{DISCUSSION}

It has been suggested that the pathophysiology of AP involves a type IV subtype $a-b$ hypersensitivity response. ${ }^{8}$ Hypersensitivity reactions are exaggerated immune responses against environmental antigens. ${ }^{9}$ In 2013, Vera et al. reported that AP patients were exposed to antigens which could trigger an allergic response, notably wood smoke and cohabitation with pets or farm animals. ${ }^{10}$ Nevertheless, other antigens that trigger the inflammatory process which causes the development of mucocutaneous lesions should be identified.

The type IV response is mediated by T lymphocytes and their soluble products in which lymphocytes that sensitized and induced to produce cytokines are recruited. ${ }^{9}$ The subtype $\mathrm{b}$ response corresponds to a Th2 reaction, whereby IL4, IL13, and IL5 are secreted and B cell, IgE, and IgG4 production is promoted, with the subsequent deactivation of macrophages and participation of mast cells and eosinophils. ${ }^{7}$

Our findings complement those of Martínez et al., who identified mast cells and eosinophils in AP lesions of the lip and skin. ${ }^{11}$

Notably, patients with moderate to severe lesions had elevated IgE levels, contrasting with the normal serum levels in those with minor injuries. No difference was observed between the presence and severity of injury and treatment; 2 patients were not undergoing treatment with thalidomide -1 had high $\operatorname{IgE}$ levels, the other had normal levels. These variables should be examined in greater detail.

The involvement of TNF-alpha, the presence of apoptosis, and NK cell activation by IL 2 remain to be 
TABLE 2: Patients diagnosed with actinic prurigo. Clinical reactions and their relationship with the serum IgE levels.

\begin{tabular}{llllll}
\hline Patient & Age & Sex & Clinical picture & Treatment & IgE level \\
\hline 1 & 47 & Female & Severe & Thalidomide & $* 4586.75$ UI/mL \\
2 & 30 & Male & Mild & Thalidomide & 23 \\
3 & 46 & Male & Mild & Thalidomide & 23.57 \\
4 & 34 & Female & Moderate & Thalidomide & $* 669$ \\
5 & 13 & Female & Mild & Photoprotection & 8 \\
6 & 21 & Female & Mild & Topical steroid & $* 167$ \\
7 & 13 & Male & Mild & Thalidomide & 60 \\
8 & 43 & Male & Mild & Thalidomide & 68 \\
9 & 22 & Female & Mild & Thalidomide & 42 \\
10 & 22 & Male & No injuries & Thalidomide & 1.33 \\
11 & 33 & Female & Moderate & Thalidomide & $* 175$ \\
12 & 24 & Female & Severe & Thalidomide & 72488 \\
13 & 15 & Female & Moderate & Thalidomide & 76 \\
14 & 29 & Female & Mild & Thalidomide & 46 \\
15 & 41 & Male & Moderate & Thalidomide & $* 511$ \\
16 & 28 & Female & Severe & Thalidomide & $* 1649$ \\
17 & 30 & Male & Moderate & Thalidomide & $* 613$ \\
18 & 25 & Female & Severe & Thalidomide & $* 3000$ \\
19 & 11 & Female & Moderate & Thalidomide & $* 529$ \\
20 & 7 & Female & Moderate & Thalidomide & $* 230$ \\
21 & 30 & Male & Mild & Thalidomide & 80 \\
\hline
\end{tabular}

* Elevated serum levels of IgE, reference ranges (1.31-165.3 UI/mL)

TABLE 3: Association of elevated levels of IgE with moderate to severe injuries

\begin{tabular}{llll}
\hline & \multicolumn{2}{c}{ IgE levels } & \multirow{2}{*}{ Total } \\
\cline { 2 - 3 } & Normal & High & \\
\hline No injuries & 1 & 0 & 1 \\
Mild Injuries & 8 & 1 & 9 \\
Moderate & 1 & 6 & 7 \\
Severe & 0 & 4 & 4 \\
Total & 10 & 11 & 21 \\
\hline
\end{tabular}

$\mathrm{X}^{2}=14.00, \mathrm{p}=.003$ addressed. In addition, we must determine if AP patients are exposed to various antigens that trigger the disease or whether ultraviolet light is the sole causative factor.

\section{CONCLUSIONS}

In this study, IgE levels were elevated in AP patients with moderate to severe injuries, suggesting that these reactions can be attributed to a type IV subtype $a-b$ hypersensitive response. 


\section{REFERENCES}

1. Hojyo-Tomoka T, Vega-Memije E, Granados J, Flores 0, Cortés-Franco R, Teixeira F, et al. Actinic Prurigo: an update. Int J Dermatol. 1995;34:380-4.

2. Vega-Memije ME, Mosqueda-Taylor A, Irigoyen-Camacho ME, Hojyo-Tomoka MT, Domínguez-Soto L. Actinic prurigo cheilitis: clinicopathologic analysis and therapeutic results in 116 cases. Oral Surg Oral Med Oral Pathol Oral Radiol Endod. 2002;94:83-91.

3. Saeb M, Cortés R, Vega ME, Hojyo MT, Guevara ME, Dominguez L. Principales fotodermatosis en Latinoamérica. Revisión y actualización. Derm Venez. 1999;37:15-21.

4. Arrese JE, Dominguez-Soto L, Hojyo-Tomoka MT, Vega-Memije E, Cortés-Franco $\mathrm{R}$, Guevara $\mathrm{E}$, et al. Effectors of inflammation in actinic prurigo. J Am Acad Dermatol. 2001;44:957-61.

5. Hojyo-Tomoka MT, Vega-Memije ME, Cortes-Franco R, Domínguez-Soto L. Diagnosis and treatment of actinic prurigo. Dermatol Ther. 2003;16:40-4.

6. Lomonte B, Salas P, Quesada F. Determinación inmunoenzimática de los niveles séricos de inmunoglobulina $E$ en niños asmáticos de la Meseta Central de Costa Rica. Rev Costarric Cienc Méd. 1991;12:1-6.

7. Adam J, Pichler WJ, Yerly D. Delayed drug hypersensitivity: models of T-cell stimulation. Br J Clin Pharmacol. 2011;71:701-7.

8. González JC, Vázquez FJ, Rodríguez Lobato E, Farfán Morales JE, Vega Memíje ME. Determination of apoptosis in actinic prurigo by TUNEL technique. Photodermatol Photoimmunol Photomed. 2015;31:115-7.

9. Romero JG, Pereira Q, Atilio R, Canteros GE. Reacciones de hipersensibilidad. Rev Posgrado Vla. Cátedra Med. 2007,167:11-6.

10. Vera Izaguirre DS, Zuloaga Salcedo S, González Sánchez PC, Sánchez Lara K, Chávez Tapia N, Hojyo Tomoka MT, et al. Actinic prurigo: a case-control study of risk factors. Int J Dermatol. 2014;53:1080-5.

11. Martínez-Luna E, Bologna-Molina R, Mosqueda-Taylor A, Cuevas-González JC, Rodríguez-Lobato E, Martínez-Velasco MA et al. Inmunohistochemical detection of mastocytes in tissue from patients with actinic prurigo. J Clin Exp Dent. 2015; 7:656-9.

\section{MAILING ADDRESS:}

Maria Elisa Vega Memije, MD.

Calzada de Tlalpan 4800, Sección XVI

Delegación Tlalpan

México, D.F. C.P 14080

E-mail: elisavega50@gmail.com

How to cite this article: Cuevas-González JC, Lievanos-Estrada Z, Vega-Memíje ME, Hojyo-Tomoka MT, Domínguez. Soto L. Correlation of serum IgE levels and clinical manifestations in patients with actinic prurigo. An Bras Dermatol. 2016;91(1):23-6. 